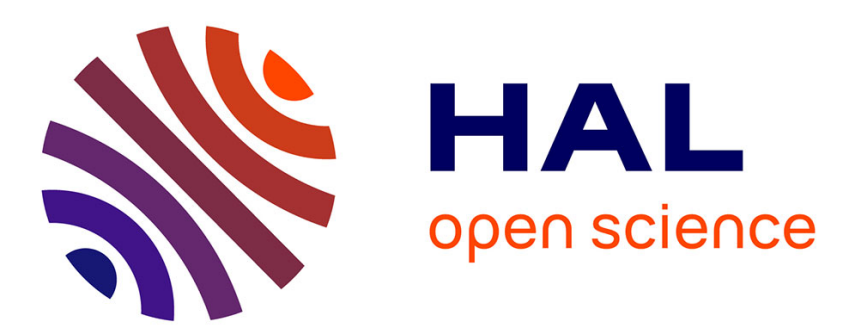

\title{
Predictors of outcome in infant and toddlers functional or behavioral disorders after a brief parent-infant psychotherapy
}

M. J. Hervé, M. Paradis, C. Rattaz, S. Lopez, V. Evrard, M. White-Koning, M. Maury

\section{To cite this version:}

M. J. Hervé, M. Paradis, C. Rattaz, S. Lopez, V. Evrard, et al.. Predictors of outcome in infant and toddlers functional or behavioral disorders after a brief parent-infant psychotherapy. European Child and Adolescent Psychiatry, 2009, 18 (12), pp.737-746. 10.1007/s00787-009-0032-9 . hal-00535158

\author{
HAL Id: hal-00535158 \\ https://hal.science/hal-00535158
}

Submitted on 11 Nov 2010

HAL is a multi-disciplinary open access archive for the deposit and dissemination of scientific research documents, whether they are published or not. The documents may come from teaching and research institutions in France or abroad, or from public or private research centers.
L'archive ouverte pluridisciplinaire HAL, est destinée au dépôt et à la diffusion de documents scientifiques de niveau recherche, publiés ou non, émanant des établissements d'enseignement et de recherche français ou étrangers, des laboratoires publics ou privés. 


\title{
Predictors of outcome in infant and toddlers functional or behavioral disorders after a brief parent-infant psychotherapy
}

\author{
M. J. Hervé · M. Paradis · C. Rattaz $\cdot$ S. Lopez \\ V. Evrard · M. White-Koning · M. Maury
}

Received: 3 May 2007 / Accepted: 31 December 2007/Published online: 19 May 2009

(C) Springer-Verlag 2009

\begin{abstract}
The efficacy of parent-child psychotherapies is widely recognized today. There are, however, less data on predictive factors for outcome in infants and toddlers and their parents. The aim of this study was to highlight predictive factors for outcome after a brief psychotherapy in a population of 49 infants and toddlers aged 3-30 months presenting functional or behavioral disorders. Two assessments were performed, the first before treatment and the second a month after the end of the therapy. These assessments included an evaluation of the child's symptoms, and of depressive or anxiety symptoms in the parents. The assessments after therapy show complete or partial improvement in the child's symptoms for nearly three quarters, and a decrease in the number of anxious and depressive mothers, and also in the number of depressive fathers. Three independent factors appear as predictive of unfavorable outcome for the child: frequency and intensity of behavioral problems and fears, and the absence of the father at more than two-thirds of consultations. The outcome for the mother is associated solely with her anxiety score at the start of the therapy. This study underlines the particular difficulties involved in the treatment of infants and toddlers presenting behavioral disturbances and emotional difficulties, and the value of involving the father in treatment.
\end{abstract}

M. J. Hervé $(\varangle) \cdot$ M. Paradis · C. Rattaz · S. Lopez ·

V. Evrard - M. Maury

Child and Adolescent Psychiatry Department,

St Eloi Hospital, CHU of Montpellier,

80 Avenue A. Fliche, 34295 Montpellier Cedex 5, France

e-mail: mj-herve@chu-montpellier.fr

M. White-Koning

Inserm U558, Université Paul Sabatier,

31073 Toulouse Cedex, France
Keywords Outcome $\cdot$ Predictors - Infant/toddler · Functional disorder $\cdot$ Behavioral disorder

\section{Introduction}

Functional disorders (sleep and feeding disorders) and behavioral disorders are the most frequent reasons for consultation for children under 3 years. Sleep disorders have been the subject of numerous studies. Reported prevalence varies from 18 to $46 \%$ in the second semester of life [1, 22, 50], and from 20 to $29 \%$ between the ages of 1 and 3 years $[4,50]$. The prevalence of behavioral disorders is reported to be between 7 and $13 \%$ [5, 26, 44]. Sleep disorders are often persistent, and associated with behavioral disorders and separation difficulties [25, 33, 50]. In a population of children aged 18-47 months seen in consultation, Thomas and Guskin [46] observed a combination of externalized and internalized symptoms in $45 \%$ of cases. Most studies have shown a significant association between these early disorders in infants and toddlers and the presence of depressive symptoms in the mother [11, 22, 34, 47].

Several types of therapeutic intervention have been developed in recent decades to treat these various difficulties. The parent-child therapies have in common to target parent-child relationships [9, 20, 21, 30, 32], despite different points of entry into the family system: representations, behaviors, or a combination of the two. The psychodynamic psychotherapies focus on the mother's representations concerning the child [13, 17, 29]: the therapist works on mother's projections onto the child, in particular on a core conflictual relationship with the child and a similar conflict in the mother's past history, in order to increase the mother's ability to differentiate her child 
from herself and to respond accurately to her child's needs. The behavior-oriented therapies, such as interactional guidance, aim to directly modify mother-infant interactions, without any reference to the mother's past history [35]: videotaped interactions of mother and infant are used by the therapist to help the mother recognize positive interactions and to develop appropriate responsiveness and confidence in her parenting role. The infant-led psychotherapies, such as the program called watch, wait, and wonder (WWW), focus on the infant and work both at representational and at behavioral level [9, 38]: the mother is asked to observe and follow her infant's initiations during a first part of the session, then with the therapist to discuss her observations and experiences of the infant-led play, trying to understand the themes and relational issues that occurred.

Despite some interest in parent-child therapies, there has thus far been little research in the area. The outcomes of these therapies have been generally positive, even 6 months or more after the end of the treatment $[9,10,13$, $31,42]$. In a population of children aged 30 months or less with functional or behavioral disorders, Robert-Tissot et al. [42] compared infant-parent psychodynamic psychotherapy and interactional guidance. They showed that the main benefits were seen in the child's symptoms. The results indicated also an improvement in mother-child interactions (the mothers became more sensitive, less intrusive, and the children more cooperative), and an improvement in maternal self-esteem, with a decrease in negative affects. Only a few differential treatment effects were observed: there was a greater improvement in self-esteem in psychodynamic psychotherapy and a greater improvement in maternal sensitivity in interactional guidance. Cohen et al. [9, 10], in a similar population, compared mother-infant psychodynamic psychotherapy and infant-led psychotherapy (WWW). In both interventions, positive effects were observed in infant symptoms, parenting stress, maternal intrusiveness and mother-infant conflict. The WWW group showed greater improvements at the end of treatment in attachment relationships, cognitive development and emotion regulation in the infants and maternal depression, but the other group showed the same gains at the 6 months follow-up.

These studies on efficacy did not generally explore the predictive factors for outcome. The only factor evidenced in a clinical population of young children was the type of disorder in the child, behavioral disorders improving less markedly than functional disorders [42]. To form an idea of potential predictive factors, reference has to be made to other populations, and in particular young children exposed to maternal depression and/or unfavourable socioeconomic conditions receiving preventive interventions, or children and adolescents undergoing psychotherapy.
In preventive interventions with depressed mothers or multi-problem families, the factors studied relate either to population characteristics, or to characteristics of the therapeutic intervention. Two meta-analyses [2, 49] of therapeutic interventions on parental sensitivity and infant attachment security showed that the most effective interventions were focused on sensitive maternal behavior, lasted less than 16 sessions and started after the age of 6 months. Interventions involving both parents appear to be more effective than interventions focusing on mothers only. Cicchetti et al. [6, 7], in a population of depressed mothers and their toddlers did not find any effect of treatment length on attachment security and cognitive development in the children studied. Other studies have shown that the quality of the implication of the mother in the treatment process [19, 24, 31] and the support of the partner [19] were associated with better outcome. The sex of the child, the mother's educational status, and the presence of environmental risk factors have shown no relationship with outcome $[2,7]$.

In child or adolescent therapies, most studies do not identify demographic variables as predictive of outcome, except for age, younger children showing greater improvement [14, 45, 48]. A poorer outcome is found in case of disruptive disorders (in particular conduct disorders or attention deficit hyperactivity disorder) than in case of emotional disorders [15]. Greater severity [14, 48] and difficulties in the family (parental separation, psychiatric disorders in parents, dysfunctions in family relationships) [15, 23, 48] are also associated with poorer prognosis. In a population of children with sleep disorders, managed using behavioral methods, Jones et al. [23] found that successful outcome was associated with absence of marital discord and attendance of both parents at treatment sessions.

The aim of the present study was to determine predictive factors for outcome in a population of young children presenting functional or behavioral disorders and having been subjected to a short therapeutic intervention targeting both representations and behaviors. Indeed, better knowledge of these factors appears important to enable detection of populations at risk, and adaptation of treatment offered. The choice of the factors studied was based on the main studies cited above.

\section{Methods}

\section{Sample}

All infants and toddlers aged 3-30 months consulting for the first time in a child psychiatry department in Montpellier between June 2002 and June 2004 for 
functional or behavioral disorders were included in the study. Children presenting severe medical history, a suspicion of ill-treatment, an invasive developmental problem, or having a parent with a psychotic disorder, were excluded. Of the 74 families complying with inclusion criteria, 56 agreed to participate $(76 \%)$. One family was excluded during the course of the study because they withdrew their consent. Parents all provided written consent for their participation. This study received approval from the Montpellier ethics committee relating to the protection of individuals taking part in research. The research was proposed by telephone to families complying with inclusion criteria, shortly after their request for an appointment. If they accepted, the family was seen immediately before the first consultation appointment by a researcher, independent from the intervention team, to make a first assessment, and again at the end of the therapeutic intervention to perform the second assessment.

\section{Description of the therapeutic intervention}

The treatment consisted in therapeutic consultations conducted by two experienced therapists. The technique used involves the integration of different models based on the theories concerning early development, the attachment theory, and psychodynamic theories $[16,27,30]$. The number of consultations was not pre-defined, but was less than ten in most cases. The therapy is conducted with the mother or both parents. If the father is present at the outset, work generally proceeds with him and the mother. If he is absent at the first consultation, his presence is suggested, most often by the therapist, according to subjects broached and how secure the mother feels about bringing the father into the therapeutic process. The main objectives of the therapy are reduction of the child's symptom, improvement of the child's emotional functioning, reduction of the parents' psychological suffering, and improvement of parentchild relationships. The therapeutic process involves the exploration of the representations and emotions of the parents concerning their infant or toddler, with a focus on the interactions occurring in the course of the consultation. The therapist aims to work on the following aspects of the child-parent relationship: the parents' sensitivity and understanding, the quality of their responses to signals from, and needs of, the child, and the reinforcement of existing positive interactions. Parental history is usually explored, but while it can help the therapist to gain a better understanding of the current dysfunctional relational patterns and to resolve this dysfunction, it is not always the subject of any interpretation. The intervention also aims to improve relational functioning and mutual support between the parents. Security in the therapeutic relationship and in particular therapist empathy is essential elements in the treatment, and act as a "corrective emotional experience" [29].

\section{Instruments}

Evaluations of the child's symptoms and evaluations of depressive or anxious symptoms in the parents were performed immediately before the first appointment for a consultation, and 1 month after the end of consultations. Socio-demographic and clinical data were collected at the time of the first assessments.

The following instruments were used:

- Symptom check-list (SCL [40]). This is a questionnaire completed by the parent(s) with the researcher, enabling quantification of the most common psycho-functional symptoms in children under three, according to frequency, duration, and intensity in the course of the previous 4 weeks. This questionnaire has been validated in a clinical population and a general control population [33, 41]. Six areas are explored: sleep, feeding, digestion, behavior, fears and shyness, and separation. Each question is answered on a five-point scale (ranging from $1=$ never or slight to $5=$ nearly always or considerable). A summary sub-score is computed for each area of symptoms. A global score is obtained by averaging these six sub-scores. The repercussions of the child's symptoms on the family are also assessed with a score from 1 to 5 . The presence of a problem in any given domain was registered if the SCL subscore was greater than 2.5 [threshold chosen in accordance with the results obtained by Cramer et al. (1990)].

- Hospital anxiety and depression scale (HAD [28]). This self-administered questionnaire comprising 14 items enables identification of anxious or depressive symptoms in adults, and evaluation of severity. It was developed by Zigmond and Snaith, and translated and validated in French by Lépine. Several studies have shown its usefulness in assessing the evolution over time of anxious and/or depressive symptoms. Each item is coded on a four-point scale yielding two scores ranging from 0 to 21 , one for depression and the other for anxiety. Anxiety or depression is considered certain for a sub-score of 11 or more, and possible for a subscore between 8 and 10 .

Data analysis

The child's outcome was determined from the six final SCL sub-score values and from the comparison with the initial sub-scores for the one or two main symptoms (functional and/or behavioral) presented at the time of the initial assessment. 
Outcome was considered to be

- favorable (A) if the child was asymptomatic at the final assessment, i.e., no sub-score over 2.5 ;

- unfavorable (C) in the absence of any improvement in initial main symptom in the child, i.e., aggravation or a decrease of less than 0.5 ; or if at least one final subscore was four or more;

- intermediate (B) in all other cases, which correspond either to a partial improvement of the initial main symptom, or complete improvement of this symptom and appearance of a moderate symptom $(<4)$ in another area.

The outcomes for the mother and the father were assessed using final anxiety and depression scores. The result was considered favorable if the two final HAD scores were below eight, and unfavorable otherwise.

The factors associated with infant/toddler outcome and maternal outcome were studied. Given the data in the literature, the purpose was to test the hypothesis of a link between outcome and the following variables: gender and age of the child, socio-professional category and marital status of parents, type and severity of the child's disorder(s), psychological difficulties in parents, participation of the father in treatment, and number of sessions completed. Comparisons were conducted using $\chi^{2}$ or Fischer tests for qualitative variables and the non-parametric Kruskall Wallis or Mann Whitney tests for quantitative variables. Multivariate stepwise logistic regression analyses were then performed, using the variables at the $10 \%$ threshold in univariate analysis. Only variables at the 5\% threshold were retained in the final multivariate analysis. The associations between the child's symptoms and those of the parents at the time of the initial evaluation and at the time of the final evaluation were also studied using Spearman's correlation coefficients (since a normal distribution could not be assumed). The association between child and parent outcome was studied using a Fischer test. As there was no information enabling an estimate of the therapeutic failure rate, the number of subjects required was not calculated a priori. Fourteen individuals per group were required to obtain a power of $90 \%$ to evidence a significant association. The statistical analyses were performed using STATA software.

\section{Results}

Description of the population

\section{Socio-demographic and clinical data}

Of the 55 families included in the study, 50 completed the whole research procedure, and 49 were analyzed (for one family the initial evaluation was incomplete). Of the five families for whom a final evaluation was not possible, four had broken off therapy.

The children, 31 boys (63.3\%) and 18 girls $(36.7 \%)$ were aged 4-29 months at the time of the first interview (mean 18.8 months, SD 6.5). They presented a functional disorder (sleep or feeding disorders) in 33 cases (67.3\%) and a behavioral disorder (crying fits, agitation, aggression and temper tantrums) in 16 cases $(32.6 \%)$. Among the children with functional disorders, 17 also presented an emotional disorder (separation anxiety). The vast majority of the children with a behavioral disorder (14 or $87.5 \%$ ) presented at least one other symptom (functional disorder, fears, separation anxiety and/or digestive problems); altogether, 31 children $(63.3 \%)$ presented more than one symptom.

Of the majority of the parents, $92 \%$ were living as a couple ( $51 \%$ were married, $41 \%$ living with a partner); $8 \%$ were separated. The socio-professional categories of the head of the family were distributed as follows: $8.2 \%$ self-employed artisans or retail traders, $30.6 \%$ in managerial or executive employment or intellectual professions, $42.8 \%$ were in intermediate professions, $12.2 \%$ were unskilled workers, and $6.1 \%$ had no activity. The mean age of the fathers was $32.7(\mathrm{SD}=6.2)$ and that of the mothers $30.2(\mathrm{SD}=4.8)$.

The mean number of consultations was 3.1 ( $\mathrm{SD}=2.0$; range 1-9) over a mean duration of 5 months. The father accompanied the mother for more than two-thirds of the consultations in 23 cases $(46.9 \%)$, between one and twothirds of consultations in 6 cases $(12.2 \%)$, and for one-third of consultations or less in 7 cases $(14.3 \%)$. The mother always came alone with the child in 13 cases $(26.5 \%)$.

\section{Outcome after therapy}

At the time of the final evaluation, 29 children, or $59.2 \%$, had a favorable outcome. Six children, or $12.2 \%$, had an intermediate outcome. Unfavorable outcome concerned 14 children, or $28.6 \%$. For the mothers, 24 (49\%) presented anxious or depressive symptoms at the final assessment (24 presented anxious symptoms compared to 33 at the initial assessment; 5 presented depressive symptoms compared to 12 initially). Nine fathers $(25.7 \%)$ presented symptoms at the time of the final assessment ( 8 presented anxious symptoms compared to 13 at the initial assessment, and 3 presented depressive symptoms compared to three also in initial assessment).

Factors associated with outcome

\section{Child outcomes}

The factors associated with the child's outcome were examined using univariate followed by multivariate analyses. Table 1 shows that the children for whom outcome 
Table 1 Factors associated with child outcome: Univariate and multivariate analyses (stepwise backward logistic regression analysis)

\begin{tabular}{|c|c|c|c|c|c|c|c|c|c|c|}
\hline \multirow[t]{3}{*}{ Factors } & \multicolumn{6}{|c|}{ Child outcome } & \multirow[t]{3}{*}{$P$} & \multicolumn{3}{|c|}{ Unfavorable outcome } \\
\hline & \multicolumn{2}{|c|}{ Favorable } & \multicolumn{2}{|c|}{ Intermediate } & \multicolumn{2}{|c|}{ Unfavorable } & & \multirow[t]{2}{*}{ Adj $\mathrm{OR}^{\mathrm{a}}$} & \multirow[t]{2}{*}{$95 \% \mathrm{CI}$} & \multirow[t]{2}{*}{$P$} \\
\hline & $n$ & $\%$ & $n$ & $\%$ & $n$ & $\%$ & & & & \\
\hline \multicolumn{11}{|l|}{ Marital status } \\
\hline Separated & 0 & 0 & 0 & 0 & 4 & 100 & 0.009 & & & \\
\hline Not separated & 29 & 64.4 & 6 & 13.3 & 10 & 22.2 & & & & \\
\hline \multicolumn{11}{|l|}{ Type of disorder } \\
\hline Functional disorder & 23 & 69.7 & 6 & 18.2 & 4 & 12.1 & 0.001 & & & \\
\hline Behavioral disorder & 6 & 35.7 & 0 & 0.0 & 10 & 62.5 & & & & \\
\hline \multicolumn{11}{|l|}{ Initial maternal anxiety } \\
\hline$<8$ & 13 & 81.2 & 2 & 12.5 & 1 & 6.2 & 0.03 & & & \\
\hline$\geq 8$ & 16 & 48.5 & 4 & 12.1 & 13 & 39.4 & & & & \\
\hline \multicolumn{11}{|l|}{ Presence of father at } \\
\hline$<66.7 \%$ of consultation & 13 & 50.0 & 2 & 7.7 & 11 & 42.3 & 0.06 & 1 & & \\
\hline \multirow[t]{2}{*}{$\geq 67 \%$ of consultation } & 16 & 69.6 & 4 & 17.4 & 3 & 13.0 & & 0.17 & $(0.03-0.99)$ & 0.05 \\
\hline & M & SD & M & SD & M & SD & & & & \\
\hline Initial behavior & 2.0 & 0.7 & 2.1 & 0.2 & 2.7 & 0.8 & 0.007 & 3.36 & $(1.05-10.79)$ & 0.04 \\
\hline Initial fears & 1.7 & 0.5 & 1.9 & 0.5 & 2.4 & 0.9 & 0.01 & 4.19 & $(1.24-14.08)$ & 0.02 \\
\hline Initial global SCL score & 2.0 & 0.4 & 2.1 & 0.1 & 2.5 & 0.5 & 0.005 & & & \\
\hline
\end{tabular}

${ }^{a}$ Final multivariate model: factors associated with unfavorable child outcome

was unfavorable more often presented behavioral disorders and/or fears, and a higher initial global SCL score, and that they were more likely to have separated parents, a mother with a high anxiety score and a father absent from consultations or present at only a few.

Child outcome was not, however, associated significantly with the age and gender of the child, or with parental age and occupation of the head of the family, or with the initial score for the child's main symptom, the initial sleep, feeding, digestion, separation and family repercussions sub-scores, the maternal depression score, the initial depression and anxiety scores for the father, or, finally, the number of consultations.

It was not possible to take account of marital status in multivariate analysis because all children of separated parents had an unfavorable outcome (number $=0$ so that the calculation was impossible). Following this analysis, the sub-scores for behavior, fears, and the presence of the father at more than two-thirds of the consultations, remain independently associated with the child's outcome (Table 1): outcome was more often unfavorable when the behavior subscore and the fears sub-score were higher and when the father had taken part in less than two-thirds of the consultations.

\section{Parental outcomes}

The factors associated with parental outcome were examined using univariate and multivariate analyses. Mothers with an unfavorable outcome (presence of anxious and/or depressive symptoms at the final assessment) were more likely to be separated from the child's father, had higher initial anxiety and depressive scores, and their children presented higher behavior sub-scores (Table 2). The number of consultations was lower, but not significantly so.

No significant association was found between maternal outcome and the age or gender of the child, the socioprofessional category of the mother, the presence of the father at consultations, the other initial SCL sub-scores, the initial score for the child's main symptom, or the initial global SCL score.

In the multivariate analyses, only the initial anxiety score of the mother is independently associated with maternal outcome (Table 2).

Given the small number of fathers presenting an unfavorable outcome, the factors associated with paternal outcome were not studied.

\section{Associations between parent and child outcomes}

We first studied the links between child symptoms and parental symptoms in initial and final assessments. At the first assessment, the frequency of maternal psychological difficulties was greater in case of behavioral disorders in the child than in case of functional disorders: 87 versus $57.5 \%$ for anxious symptoms $(P=0.05)$, and 43.7 versus $15.1 \%$ for depressive symptoms $(P=0.04)$. Table 3 shows 
Table 2 Factors associated with maternal outcome: Univariate and multivariate analyses (stepwise backward logistic regression analysis)

\begin{tabular}{|c|c|c|c|c|c|c|c|c|}
\hline \multirow[t]{3}{*}{ Factors } & \multicolumn{4}{|c|}{ Maternal outcome } & \multirow[t]{3}{*}{$P$} & \multicolumn{3}{|c|}{ Unfavorable outcome } \\
\hline & \multicolumn{2}{|c|}{ Favorable } & \multicolumn{2}{|c|}{ Unfavorable } & & \multirow[t]{2}{*}{ Adj $\mathrm{OR}^{\mathrm{a}}$} & \multirow[t]{2}{*}{$95 \% \mathrm{CI}$} & \multirow[t]{2}{*}{$P$} \\
\hline & $n$ & $\%$ & $n$ & $\%$ & & & & \\
\hline \multicolumn{9}{|l|}{ Marital status } \\
\hline Separated & 0 & 0 & 4 & 100 & 0.05 & & & \\
\hline Not separated & 25 & 55.5 & 20 & 44.4 & & & & \\
\hline \multicolumn{9}{|l|}{ Type of disorder } \\
\hline Functional disorders & 20 & 60.6 & 13 & 39.4 & 0.07 & & & \\
\hline \multirow[t]{2}{*}{ Behavioral disorders } & 5 & 31.3 & 11 & 68.7 & & & & \\
\hline & M & SD & M & SD & & & & \\
\hline Initial behavior & 2.0 & 0.7 & 2.5 & 0.8 & 0.02 & & & \\
\hline Initial maternal anxiety & 7.0 & 2.6 & 11.7 & 3.6 & $<0.001$ & 1.82 & $(1.24-2.68)$ & 0.002 \\
\hline Initial maternal depression & 4.2 & 2.3 & 6.6 & 3.7 & 0.01 & & & \\
\hline Number of consultations & 3.5 & 2.0 & 2.7 & 1.9 & 0.09 & & & \\
\hline
\end{tabular}

${ }^{a}$ Final multivariate model: factors associated with unfavorable maternal outcome

Table 3 Correlations between SCL scores and HAD scores for the mother at initial and final assessment $(n=49)$

The bold numbers correspond to the significant correlations $(P<0.05$ or $P<0.01)$

Spearman correlation coefficients

$* P<0.05$

** $P<0.01$

\begin{tabular}{|c|c|c|c|c|}
\hline \multirow{2}{*}{$\begin{array}{l}\text { HAD } \\
\text { SCL }\end{array}$} & \multicolumn{2}{|c|}{ Initial evaluation (1) } & \multicolumn{2}{|c|}{ Final evaluation (2) } \\
\hline & Mother anxiety & Mother depression & Mother anxiety & Mother depression \\
\hline Sleeping & $0.28 *$ & 0.24 & 0.19 & $\mathbf{0 . 3 3} *$ \\
\hline Feeding & 0.13 & -0.04 & 0.20 & 0.27 \\
\hline Digestion & $0.30 *$ & $0.36 * *$ & 0.04 & 0.26 \\
\hline Behavior & $\mathbf{0 . 3 6} * *$ & 0.17 & $0.37 * *$ & 0.18 \\
\hline Fears & 0.13 & 0.12 & 0.04 & 0.07 \\
\hline Separation & 0.22 & 0.22 & 0.01 & -0.01 \\
\hline Repercussion on family & 0.01 & 0.25 & 0.15 & 0.18 \\
\hline Global score & $0.41 * *$ & $\mathbf{0 . 3 3} *$ & 0.20 & 0.21 \\
\hline
\end{tabular}

the correlations between child SCL scores and maternal HAD scores for the two assessments. It can be noted that in the initial assessment several SCL scores (sleep, digestion, behavior and total score) are significantly associated with anxiety and/or depression scores in the mother. In the final evaluation, only the behavior score is still significantly associated with the anxiety score, and the sleep score with the maternal depression score. There is, however, no significant association between the child SCL scores and paternal HAD scores, whether in the initial or the final assessment.

The association between parent and child outcomes was then studied. The child outcome score was not significantly associated with anxious symptoms in the mother at the end of the therapy (35\% of the mothers presented anxious symptoms when the child's outcome was favorable, $67 \%$ when it was intermediate, and $71 \%$ when it was unfavorable, $P=0.06$ ), or with depressive symptoms in the mother (10.3, 0 and $14.3 \%$ presented depressive symptoms when child's outcome was favorable, intermediate and unfavorable respectively, $P=1$ ). Child outcome did not appear to be associated with paternal outcome.

\section{Discussion}

The aim of this study was to study factors that were predictive of outcome for children and parents following a short therapeutic intervention in a population of infants and toddlers consulting for behavioral or functional disorders. The treatment, conducted with the infant or toddler and one or both parents, aimed to improve the psychological condition of child and parents, and their relationships, using as a starting point the representations of the parents and the interactions observed in the course of consultations within a secure therapeutic relationship.

The study population presented similar characteristics to those observed in previous similar studies using a similar 
therapeutic approach $[13,42]$, in particular a large proportion of sleep disturbances (the most frequent symptom in the present population) and the existence of co-morbidity (presence of behavioral disturbances, functional disturbances and/or emotional difficulties), which was observed in the present study for nearly two-thirds of the children $[25,33,39,46]$. There was also a large proportion of anxious and, to a lesser extent, depressive symptoms among the mothers [8, 22], as well as an association between the mental state of the mother and difficulties experienced by the child (in particular prior to the start of the therapy, and in case of behavioral disorders in the child). Anxious symptoms were present among the fathers, but to a lesser extent than among the mothers. It can be noted on the other hand that few fathers presented depressive symptoms. There was no association between the child's symptoms and the anxious or depressive state of the father; however, the small amount of data concerning these factors for the fathers does not enable conclusions to be drawn.

After the therapy, improvement is observed for both children and parents $[10,18,42]$. For around three quarters of the children, complete or partial improvement of the symptoms was observed, and around half the children returned to a level of functioning that corresponds to the SCL norm [42]. Although nearly half the mothers still presented anxiety symptoms in the final assessment, these symptoms were generally moderate, with a HAD score between 8 and 10. Conversely, for paternal depressive symptoms, while few fathers presented them, these symptoms improved only slightly or not at all.

The results concerning predictive factors for child outcome are in line with certain findings noted in the literature, in particular parental separation [14, 48], the type of disorder in the child [15, 42], and the presence of the father at consultations $[2,23]$. The intensity of the disturbances in the child (reflected here by the global SCL score) and the initial psychological condition of the mother are associated with the child's outcome in univariate analysis, but do not in this study constitute independent predictive factors since the association is no longer found in multivariate analysis. The child's age was not found to be a predictive factor in the present study, while it has been evidenced among older children $[15,45]$ at ages when symptoms may have been present for some time, and may be organised into psychopathological profiles that are more difficult to reach. The number of consultations is not associated with child outcome, but the therapy implemented was a short one, well below the threshold of 16 sessions found in the metaanalysis by Bakermans-Kranenburg et al. [2]. Finally, as in previous studies, no effect of the sex of the child was found, nor of the socio-economic category to which the parents belonged.
The less-favourable outcome for the infants and toddlers presenting behavioral disorders (as opposed to functional disturbances) in this study is in line with other data for infants [42] and for children [15]. Several authors have noted that risk factors for behavioral disorders involve a difficult temperament (characteristics specific to the child), and a more problematic parent-child relationship than is the case for functional disturbances. In particular, there is a difficulty in adjusting the distance in relation to the child, wavering between over- and under-implication [33, 43]. These disorders often reflect a process of internalization of interpersonal conflicts, which is more difficult to resolve in a short therapy centered on the relationship. The present results also show evidence of a less-favorable outcome among children presenting fears and/or shyness, which has been less widely noted in the literature. According to Thomas and Guskin [46], in children presenting fears (internalized disorder), as with behavioral disorders, there is a combination of a manifestation that is specific to the child and a dysfunctional parent-child relationship. In the population of this study, most of the infants and toddlers presented multiple symptoms in different areas of functioning, which could reflect major affective distress and difficulties in organizing efficient protective strategies. In these situations, it would be worthwhile studying the underlying therapeutic processes in a more precise manner, and in particular the quality of the therapeutic alliance with the parents, so as to obtain better understanding of what it was that prevented the therapist from offering efficient treatment.

The impact of paternal attendance at consultations is a particularly interesting result, and is in line with studies conducted in different populations $[2,23]$. One of the issues is the reasons underpinning the presence or absence of the fathers. The absence of the father does not appear to be related to any of the initial variables in the present study, except for marital status for obvious reasons. In the case of separation of the parents, only the mothers were seen in consultation, and in addition these were situations in which the father had no contact with the child, which is a known risk factor for difficulties in young children. It can be noted that this study did not explore agreement or harmony between the parents (either in relation to the couple per se, or parental harmony in dealings with the child, or agreement on the treatment). This might prove to be better in situations where the father attends consultations, thus itself contributing to a more favorable outcome for the child. It can also be noted that the frequency of paternal participation in consultations is predictive of outcome for the child, but not for the mother. This could be in favor of an impact of the presence of the father on elements other than that of reassuring the mother. The importance of the implication of the father in treatment is more and more 
widely recognized. When the father is present, it enables father-child relationships to be broached, as well as relationships between parents. Indeed, the child does not grow up in a dyad, but belongs to a family matrix that is larger from the outset, in which a set of individuals and subsystems interact. Barrows [3] emphasizes the fact that clinicians have long neglected the "ghosts into the nursery" [17] brought in by the father. In addition, several authors have drawn attention to the importance for the child's development not only of the child's relationship with each parent, but also of the relationship within the parental couple itself [3, 12]. Minde and Tidmarsh [37] found that $43 \%$ of the families consulting for behavioral disorders in toddlers and young children aged 1548 months presented marital problems. The way in which the parents are able to coordinate their respective investment with the child, i.e., the quality of "co-parenting", also seems essential in the child's development [36]. Co-parenting can only really be assessed and supported if the two parents are present during the therapy. However, in situations where the father is absent at the outset, it is not necessarily a case of ensuring that he attends the second consultation, but rather of working on the possibility of his implication at a given moment. Assessing what this right moment might be for mother and child is probably an important issue.

For predictive factors relating to maternal outcome, it can be noted that they are not the same as for the child. Maternal outcome is not associated with the initial child fear score nor the presence of the father in consultations. It is linked to marital status, presence of a behavioral disorder in the child, and above all to the mother's state of anxiety at the initial assessment, the only significant factor in multivariate analysis.

Finally, it is noteworthy that child outcome is not significantly associated with the final scores for anxiety and for depression in the mother. Although the small number of cases involved does not enable strong conclusions to be drawn, these results may reflect a decrease in the reciprocal influence of difficulties experienced by mother and child (also suggested by the smaller number of correlations between the SCL and the maternal HAD scores in the second assessment compared to the first). This is also in line with the data from the study by Robert-Tissot et al. [42].

This study presents preliminary results that require caution in interpretation because of the absence of a control group, the small size of the sample and uncertainly as to its representativeness since the study population accounted for only $66 \%$ of the potentially eligible children. These results need to be confirmed on a larger population. The study is also restricted in scope by the age range and the variety of disorders presented by the children. The population does, nevertheless, correspond to the majority of young children seen in child-psychiatric consultation. It would be interesting to select a more homogeneous group of children for age and symptoms, so as to derive a more accurate description of the effects of the therapy on each type of disturbance. It also appears important to assess parentchild interactions. The small number of fathers assessed did not enable sufficient data to be collected here to explore related outcomes. A complementary study on this point would be worthwhile, given the importance of paternal attendance in consultations that has been evidenced here. Finally, the fact that a single cut-off score was used on the SCL whatever the age of the child is open to discussion, in particular for separation difficulties. Nevertheless, to classify a child's outcome as unfavorable, only scores of four or more were retained. Thus this group does not include children with separation anxiety falling into a normal range.

Despite these limitations, this study has made it possible to evidence risk factors for unfavorable outcome, which could be taken into account to improve the results of therapy. The results require confirmation, but do underline the fact that situations in which the infant or toddler presents behavioral disorders or fears (generally in association with other disorders), and where the mother is particularly anxious and separated from the partner or spouse, are situations that are more difficult to treat. In these cases, it would be valuable to study the terms of intervention that are the best suited to promoting a good working alliance so as to offer appropriate treatment. For frontline healthcare actors, these results underline the importance of not underestimating maternal anxiety, and of refraining from the assumption that the separation of the parents and the role of the father in early development are factors of minor importance. Future studies should assess whether early detection of behavioral and emotional disorders can indeed improve treatment. For mental health professionals, the results of this study pinpoint the interest of giving greater consideration to the implication of the father in treatment, and to determining the most opportune moment to mobilize such participation.

Acknowledgments This research was funded by the CHU (University Hospital Center) of Montpellier.

\section{References}

1. Amstrong KL, Quin RA, Dadds MR (1994) The sleep patterns of normal children. Med J Aust 1:202-206

2. Backermans-Kranenburg MJ, van IJzendoorn $\mathrm{MH}$, Juffer $\mathrm{F}$ (2003) Less is more: Meta-Analyses of Sensitivity and Attachment Interventions in Early Childhood. Psychol Bull 129(2):195215

3. Barrows P (2004) Fathers and families: Locating the ghost in the nursery. Infant Ment Health J 25(5):408-423 
4. Bax MCO (1980) Sleep disturbance in the young child. BMJ 141:1177-1179

5. Charlton T, Abraham M, Jones K (1995) Prevalence rates of emotional and behavioural disorder among nursery class children in St Helen, South Atlantic: an epidemiological study. J Soc Behav Pers 10:273-280

6. Cicchetti D, Toth SL, Rogosch FA (1999) The efficacy of toddler-parent psychotherapy to increase attachment security in offspring of depressed mothers. Attach Hum Dev 1(1):34-66

7. Cicchetti D, Rogosch FA, Toth SL (2000) The efficacy of toddler-parent psychotherapy for fostering cognitive development in offspring of depressed mothers. J Abnorm Child Psychol 28(2):135-148

8. Civic D, Holt VL (2000) Maternal depressive symptoms and child behavior problems in a nationally representative normal birthweight sample. Matern Child Health J 4(4):215-221

9. Cohen NJ, Muir E, Lojkasek M, Muir R, Parker CJ, Barwick M, Brown M (1999) Watch, Wait, and Wonder: testing the effectiveness of a new approach to mother-infant psychotherapy. Infant Ment Health J 20(4):429-451

10. Cohen NJ, Lojkasek M, Muir E, Muir R, Parker CJ (2002) Six-months follow-up of two mother-infant psychotherapies: Convergence of therapeutic outcomes. Infant Ment Health J 23(4):361-380

11. Cowan P, Cowan CP (2001) A couple perspective on the transmission of attachment patterns. In: Clulow C (ed) Adult attachment and couple psychotherapy. Brunner-Routledge, London, pp 62-82

12. Cox AD, Puckering C, Pound A, Mills M (1987) The impact of maternal depression in young children. J Child Psychol Psychiatry $28: 917-928$

13. Cramer B, Robert-Tissot C, Stern DN, Serpa-Rusconi S, De Muralt M, Besson G, Palacio-Espasa F, Bachmann JP, Knauer D, Berney C, D'Arcis U (1990) Outcome Evaluation in Brief Mother-Infant Psychotherapy: a Preliminary Report. Infant Ment Heath J 11(3):278-300

14. Emslie GJ, Mayes TL, Laptook RS, Batt M (2003) Predictors of response to treatment in children and adolescents with mood disorders. Psychiatr Clin North Am 26(2):435-456

15. Fonagy P, Target M (1994) The efficacy of psychoanalysis for children with disruptive disorders. J Am Acad Child Adolesc Psychiatry 33(1):45-55

16. Fraiberg S (1980) Clinical studies in infant mental health: The first year of life. Basic Books, New-York

17. Fraiberg S, Adelson E, Shapiro V (1976) Ghosts in the nursery: a psychoanalytic approach to the problems of impaired motherinfant relationships. J Am Acad Child Psychiatry 14:387-421

18. Hall WA, Clauson M, Carty EM, Janssen PA, Saunders RA (2006) Effects on parents of an intervention to resolve infant behavioural sleep problems. Pediatr Nurs 32(3):243-250

19. Heinicke CM, Goorsky M, Moscov S, Dudley K, Gordon J, Schneider C, Guthrie D (2000) Relationship-based intervention with at-risk mothers: factors affecting variations in outcome. Infant Ment Health J 21(3):133-155

20. Hiscock H, Wake M (2001) Infant sleep problems and postnatal depression: a community based study. Pediatrics 107:1317-1322

21. Hofacker NV, Papousek M (1998) Disorders of excessive crying, feeding, and sleeping: the Munick interdisciplinary research and intervention program. Infant Ment Health J 19(2):180-201

22. Hopkins J (1992) Infant-parent psychotherapy. J Child Psychother 18(1):5-19

23. Jones DP, Verduyn CM (1983) Behavioral management of sleep problems. Arch Dis Child 58(6):442-444

24. Korfmacher J (1994) The relationship between participant and treatment characteristics and outcome in an early intervention program. Unpublished doctoral dissertation, University of Minnesota, USA

25. Lam P, Hiscock H, Wake M (2003) Outcomes of infant sleep problems: a longitudinal study of sleep, behavior, and maternal well-being. Pediatrics 111(3):203-207

26. Lavigne JV, Binns HJ, Christoffel KK, Rosenbaum D, Arend R, Smith K, Hayford JR, McGuire PA (1993) Behavioral and emotional problems among preschool children in paediatric primary care: prevalence and paediatricians' recognition. Pediatrics 91(3):649-655

27. Lebovici S (1983) Le nourrisson, la mère et le psychanalyste. Les interventions précoces. Le Centurion, Paris

28. Lepine JP (1996) L'échelle HAD. In: Guelfi JD (ed) L'évaluation clinique standardisée en psychiatrie. Editions Médicales Pierre Fabre, tome 1, pp 367-374

29. Lieberman AF (1992) Infant-parent psychotherapy with toddlers. Dev Psychopathol 4:559-574

30. Lieberman AF, Pawl JH (1993) Infant-parent psychotherapy. In: Zeanah C (ed) Handbook of infant mental health. The Guilford Press, New-York, pp 427-442

31. Lieberman AF, Zeanah CH (1999) Contributions of attachment theory to infant-parent psychotherapy and other interventions with infants and young children. In: Cassidy J, Shaver PR (eds) Handbook of attachment. Theory, research and clinical applications. The Guilford Press, New York, pp 555-574

32. Lieberman AF, Weston DR, Pawl JH (1991) Preventive intervention and outcome with anxiously attached dyads. Child Dev 62(1):199-209

33. Lüthi Faivre F, Sancho Rossignol A, Rusconi-Serpa S, Knauer D, Palacio Espasa F, Robert-Tissot C (2005) Troubles du comportement entre 18 et 36 mois : symptomatologie et psychopathologie associées. Neuropsychiatrie de l'enfance et de l'adolescence 53:176-185

34. Marchand JF, Hock E (1998) The relation of problem behaviors in preschool children to depressive symptoms in mothers and fathers. J Genet Psychol 159:353-366

35. Mc Hale J, Fivaz-Depeursinge E (1999) Understanding triadic and family group interactions during infancy and toddlerhood. Clin Child Fam Psychol Rev 2(2):107-127

36. McDonough SC (1995) Promoting positive early parent-infant relationships through interaction guidance. Child Adolesc Psychiatr Clin North Am 4(3):661-672

37. Minde K, Tidmarsh L (1997) The Changing Practices of an Infant Psychiatry Program: the McGill Experience. Infant Ment Health J 18(2):135-144

38. Muir E (1992) Watching, waiting and wondering: applying psychoanalytic principals to mother-infant intervention. Infant Ment Health J 13:319-328

39. Richman N (1981) A community survey of characteristics on one- to two-year-olds with sleep disruptions. J Am Acad Child Adolesc Psychiatry 20:281-291

40. Robert-Tissot C, Rusconi-Serpa S, Bachmann JP, Besson G, Cramer B (1989) Le questionnaire "Symptom check-list". Evaluation des troubles psycho-fonctionnels de la petite enfance. In: Lebovici S, Mazet P, Visier JP et al (eds) L'évaluation des interactions précoces entre le bébé et ses partenaires. Eshel, Paris, pp 179-215

41. Robert-Tissot C, Rusconi-Serpa S, De Muralt M, Stern D, Cramer B (1991) Traitement des troubles fonctionnels dans la petite enfance. Cahiers Psychiatriques Genevois 11:109-123

42. Robert-Tissot C, Cramer B, Stern DN, Rusconi-Serpa S, Bachmann JP, Palacio-Espasa F, Knauer D, de Muralt M, Berney C, Mendiguren G (1996) Outcome evaluation in brief mother-infant psychotherapies: report on 75 cases. Infant Ment Health Journal 17(2):97-114 
43. Sanson A, Prior M (1999) Temperament and behavioural precursors to oppositional defiant disorder and conduct disorder. In: Quay HC, Hogan AE (eds) Handbook of disruptive behaviour disorders. Kluwer Academic/Plenum Publishers, New York, pp 397-417

44. Stallard P (1993) The behaviour of 3-year-old children: a research note. J Child Psychol Psychiatry 34:413-421

45. Target M, Fonagy P (1994) The efficacy of psychoanalysis for children: prediction of outcome in a developmental context. J Am Acad Child Adolesc Psychiatry 33(8):1134-1144

46. Thomas JM, Guskin KA (2001) Disruptive behavior in young chidren: what does it mean? J Am Acad Child Adolesc Psychiatry 40(1):44-51
47. Thome M, Skuladottir A (2005) Evaluating a family-centred intervention for infant sleep problems. J Adv Nurs 50(1):5-11

48. Turgay A (1990) Treatment outcome for children and adolescents with conversion disorder. Can J Psychiatry 35(7):585-589

49. Van IJzendoor MH, Juffer F, Duyvesteyn MGC (1995) Breaking the intergenerational cycle of insecure attachment: A review of the effects of attachment-based interventions on maternal sensitivity and infant security. J Child Psychol Psychiatry 2:225-248

50. Zuckerman B, Stevenson J, Bailey V (1987) Sleep problems in early childhood: continuities, predictive factors and behavioral correlates. Pediatrics 80:664-671 